\title{
Current status of the diagnosis and treatment of hemophagocytic lymphohistiocytosis in adults
}

\author{
Yu Ri Kim ${ }^{1}$, Dae-Young Kim ${ }^{2}$ \\ ${ }^{1}$ Division of Hematology, Department of Internal Medicine, Yonsei University College of Medicine, ${ }^{2}$ Department of Internal \\ Medicine, Ewha Womans University College of Medicine, Seoul, Korea
}

p-ISSN 2287-979X / e-ISSN 2288-0011 https://doi.org/10.5045/br.2021.2020323 Blood Res 2021;56:S17-S25.

Received on December 17, 2020

Revised on February 22, 2021

Accepted on February 25, 2021

\begin{abstract}
Hemophagocytic lymphohistiocytosis (HLH) is a syndrome of defective apoptosis, a disruption of the regulatory pathway that terminates immune and inflammatory responses. Fever, cytopenia, splenomegaly, and/or hemophagocytosis are typical findings of this syndrome. HLH can be induced by genetic disorders (familial) or secondary causes. Familial HLH is rare, while secondary causes in adults include infection, autoimmunity, and malignancy. HLH in adults tends to be confused with or misdiagnosed as sepsis, mainly due to similar clinical manifestations and laboratory findings, which make it difficult to diagnose HLH rapidly and adopt immunosuppressive agents and/or chemotherapy adequately. Treatment of pediatric $\mathrm{HLH}$ using $\mathrm{HLH}-2004$ or multi-agent chemotherapy can be applied in adult patients, although the dose and type of drug need to be adjusted. It is highly recommended that allogenic hematopoietic stem cell transplantation should be used in patients who become reactivated or are refractory to the initial treatment as soon as possible to improve survival. Future clinical trials are warranted to determine more suitable treatments for adult patients with HLH.
\end{abstract}

Key Words Hemophagocytic lymphohistiocytosis, Hemophagocytic syndrome

\section{INTRODUCTION}

Hemophagocytic lymphohistiocytosis (HLH) is a group of diseases belonging to histiocytosis syndrome [1]. It manifests as high fever and pancytopenia, resulting in the enlargement of organs such as the liver/spleen, as well as liver dysfunction. It causes a severe inflammatory reaction in the whole body. It is not a disease but rather a consequence of an ineffective immune response [2]. Many patients have low blood pressure, which does not respond to a booster. Thus, treatments such as the administration of broad-spectrum antimicrobial agents are often provided, as it is considered to be an infection accompanied by sepsis. The condition is sometimes diagnosed at a late stage. HLH was previously thought to occur mainly in children, with an incidence rate of 1 per 800,000 per year, with geographic variation [3]. Although the incidence rate in adults is not known exactly, it is thought that many unexplained severely ill adult patients with multiple organ failure and high fever may have had HLH [4]. This literature review focuses on the diagnosis and management of patients with secondary HLH.

\section{CLINICAL FEATURES}

It is difficult to define one characteristic symptom that is common to patients with HLH. However, many patients are admitted to the hospital due to high fever $\left(>38.5^{\circ} \mathrm{C}\right)$. This is one of the symptoms that must appear during the preclinical process of HLH. A relatively typical pattern is that a patient with cytopenia and fever has an enlarged spleen. In patients with such findings, HLH is suspected and diagnostic procedures should promptly proceed.

The liver and spleen are the organs most frequently involved in HLH [3]. Aspartate aminotransferase (AST) and alanine aminotransferase (ALT) and/or bilirubin levels are elevated. This is often associated with unexplained fulminant hepatitis or liver failure. In particular, liver involvement could lead to ascites, sinusoidal obstruction, and encephalopathy. These findings are often mistaken for severe hepatitis with increased AST/ALT and bilirubin levels [5].

In addition to the liver or spleen, the lungs, intestines, kidneys, and skin are the frequently involved organs. Respiratory distress syndrome and renal failure are common 
manifestations [6, 7]. Some patients may have neurological abnormalities such as decreased consciousness, convulsions, cranial nerve abnormalities, and ataxia from the beginning, suggesting that HLH invaded the central nervous system. In such cases, the prognosis is extremely poor $[8,9]$.

These abnormal findings usually occur simultaneously or continuously within a few days to weeks, and hematologic findings of cytopenia in the bone marrow or organs are observed. Eventually, it causes malfunction of systemic organs such as the liver and kidneys. Due to bleeding, infection, loss of consciousness, and refractory hypotension, many patients die. Some outbreaks have recently been reported in adults. Some of these cases have progressed slowly over several months and then improved briefly with the administration of immunosuppressants, but as mentioned above, if the outbreak is adequately diagnosed and not treated, the mortality rate reaches $100 \%$.

\section{PATHOGENESIS}

The main pathogenesis of HLH can be briefly be summarized as follows. It can be defined as a condition involving sustained immune/inflammatory reaction, a so-called "cytokine storm." The immune mechanism is activated by various factors such as infection, autoimmunity, or malignancies. When these trigger factors are resolved, the immune system must be inactivated to restore it to its normal state. In some cases, inactivation cannot be achieved due to an abnormality in the cell signaling pathway. Consequently, a vicious cycle of activation is repeated; this excessively stimulates immune cells that then invade normal tissues, causing organ failure, and that secrete a large amount of cytokines: interferon gamma (IFN- $\gamma)$, tumor necrosis factor- $\alpha$ (TNF- $\alpha$ ), interleukin-6 (IL-6), IL-10, and macrophage-colony-stimulating factor. These induce a severe inflammatory reaction, leading to abnormal homeostasis [10]. These inflammatory cytokines contribute to the clinical features of HLH, such as myelosuppression, lymphadenopathy, fever, and organ dysfunction [11]. Various immunological abnormalities have been observed in HLH. Defective function of cytotoxic T lymphocytes and NK cells is the main abnormality $[2,12,13] . \mathrm{CD}^{+} \mathrm{T}$ cells secrete IFN- $\gamma$, which activates macrophages (Fig. 1) [14, 15].

Genetic abnormalities known to be related to the onset of primary HLH are shown in Table 1 [16-20]. PRF1 is a gene that encodes a cell surface protein called perforin. Perforin is inserted into the cell membrane of target cells when $\mathrm{T}$ cells/NK cells kill target cells, and it forms a passage for substances such as granzyme, which induces cell death. Therefore, when PRF1 is mutated, this apoptosis-inducing function works abnormally $[21,22]$. This accounts for $50 \%$

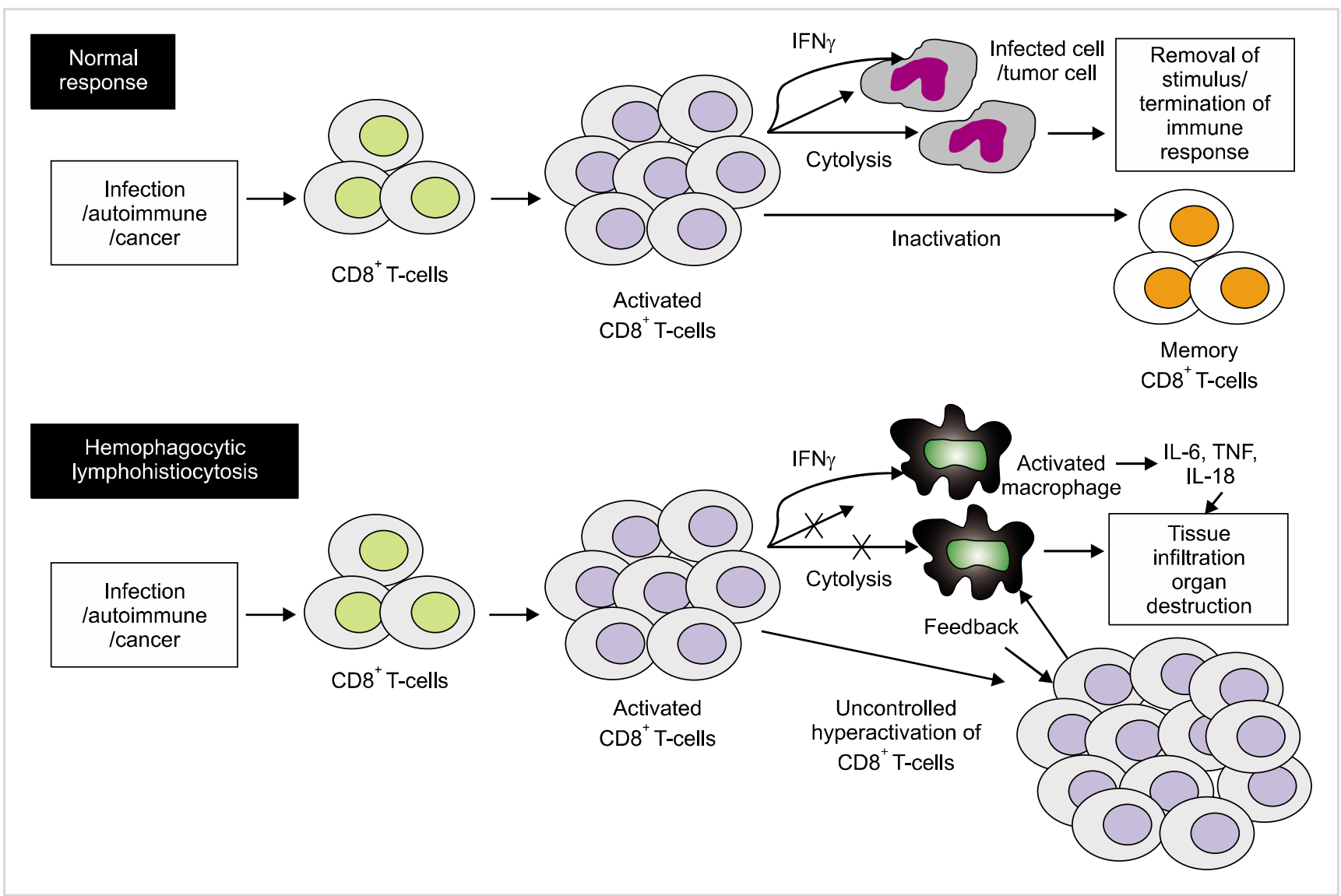

Fig. 1. The immunologic response is different between the normal host versus patients with hemophagocytic lymphohistiocytosis. 
Table 1. Gene mutations associated with hemophagocytic lymphohistiocytosis.

\begin{tabular}{cl}
\hline Disease & \multicolumn{1}{c}{ Genetic mutations } \\
\hline FHL1 & Unknown $(9 q 21.3-2)$ \\
FHL2 & PRF1, perforin $(10 \mathrm{q} 21-2)$ \\
FHL3 & MUNC13D, Munc13-4 (17q25) \\
FHL4 & STX11, Syntaxin11 (6q24) \\
FHL5 & $S T X B P 2$, Munc18-2 (19p)
\end{tabular}

Abbreviation: FHL, familial hemophagocytic lymphohistiocytosis.

of primary HLH cases among black Americans. When a mutation occurs in $M U N C 13 D$, it causes dysfunction in the extracellular release (exocytosis) of intracellular granules containing a cell signaling substance related to apoptosis, resulting in impaired apoptosis function [23]. It has been reported that more than $80 \%$ of genetic mutations causing HLD occur in MUNC13D [20], but it is a rare mutation in the West. Mutations in $S T X 11$ and $S T X B P 2$ are relatively rare genetic abnormalities.

\section{INITIATING FACTORS}

HLH is broadly divided into primary (familial) and acquired (secondary). Primary HLH more typically affects children. It is inherited and is characterized by mutations in a gene encoding a protein that forms part of the signaling system involved in the inactivation of the immune system. Acquired HLH, in contrast, is the main cause of adult HLH, and various infections such as viruses/bacteria/fungi/parasites, autoimmune diseases, and malignant tumors are the triggers [24]. Malignancy-associated HLH is more common in adults, and it has been reported that clinical manifestations of HLH occur in approximately $1 \%$ of all malignancies [25]. Malignant tumor types that commonly cause HLH are lymphoma and NK/T cell lymphoma. The latter is particularly related to the Epstein-Barr virus (EBV) and can develop a clinical pattern similar to that of HLH. In addition, the occurrence of HLH has been reported in various blood diseases such as multiple myeloma, acute leukemia, and chronic leukemia [26-28], and it can also occur with some solid cancers.

While primary HLH is rare in adults, it has been reported that genetic abnormalities such as PRF1 mutation occur in some adult cases [29]. Recently, mutations in related genes were reported in $14 \%$ of adults diagnosed with HLH and in $22 \%$ of Korean pediatric patients [30, 31]. Based on this, it has been hypothesized that acquired HLH in adults is also related to genetic abnormalities related to immune system inactivation, but the types and forms of genetic abnormalities differ from those in children, and the phenotypic expression patterns accordingly differ from those in children. Recently, attempts have been made to determine diagnostic accuracy by comprehensively investigating the expression
Table 2. Diagnostic criteria of hemophagocytic lymphohistiocytosis: HLH-2004.

Diagnosis will be established if one of either (1) or (2) is fulfilled

(1) Molecular diagnosis consistent with HLH

(2) Diagnostic criteria for HLH fulfilled (5 out of the 8 criteria shown below)

(1) Fever $\geq 38.5^{\circ} \mathrm{C}$ for $\geq 7$ days

(2) Splenomegaly $\geq 3$ finger breadth below the left subcostal margin

(3) Cytopenias affecting $\geq 2$ of 3 lineages in peripheral blood Hemoglobin $<9 \mathrm{~g} / \mathrm{L}$ Platelets $<100 \times 10^{9} / \mathrm{L}$

Absolute neutrophil count $<1.0 \times 10^{9} / \mathrm{L}$

(4) Hypertriglyceridemia and/or hypofibrinogenemia Fasting triglycerides $\geq 265 \mathrm{mg} / \mathrm{dL}$, Fibrinogen $\leq 1.5 \mathrm{~g} / \mathrm{L}$

(5) Hemophagocytosis in the bone marrow or spleen or lymph node

(6) Low or absent NK cell activity (according to the local laboratory reference)

(7) Ferritin $\geq 500 \mu \mathrm{g} / \mathrm{L}$

(8) Soluble CD25 (sIL-2 receptor) $\geq 2,400 \mathrm{U} / \mathrm{mL}$

Abbreviations: HLH, hemophagocytic lymphohistiocytosis; NK, natural killer; sIL-2, soluble interleukin-2.

patterns of genes related to the activation/deactivation of the immune system and the related cytokines, using gene expression profiles [32, 33]. In Korea, some institutions are conducting mutation tests for PRF1 and $M U N C 13 D$, and if the test is performed on patients with clinical manifestations suspected of HLH, these can facilitate differential diagnosis.

\section{DIAGNOSIS}

Since HLH is a prevalent disease in children, many studies related to the diagnosis and treatment of this condition are based on pediatric patients. For this reason, the diagnostic criteria and treatments for adults are adopted from those for children. In 1991, the "Histiocyte Society" suggested five diagnostic criteria- "fever/splenomegaly/cytopenia/hypertriglyceridemia or hypofibrinogenemia/hemophagocytosis," but the symptoms of patients appear sequentially, rather than simultaneously. In many cases, the diagnosis was difficult due to the ambiguity of the application of the diagnostic criteria at the beginning of the disease. New standard diagnostic criteria were proposed in 2004 by Henter et al. [34] to overcome this problem: 1) a gene mutation related to HLH was identified, or 2) NK cell activity, serum ferritin, and blood levels of the soluble interleukin-2 receptor were added to the existing five criteria. Therefore, diagnosis could be made when more than five of the eight criteria were satisfied (Table 2). In adult HLH, there is no separate diagnostic standard, and case reports and small-scale studies for adults also borrow and apply pediatric standards in clinical practice. In the biopsy of bone marrow, liver, and lymph 
nodes, infiltration of histiocytes and lymphocytes and hemophagocytosis have been observed [35].

In practice, adult HLH patients are often diagnosed in one of the following situations. First, hemophagocytosis was confirmed in the bone marrow examination performed while finding the cause of unknown fever. Second, hemophagocytosis was confirmed in the process of liver biopsy for unexplained liver failure. A high level of serum ferritin administered accidentally in a situation can be suspected as one of the manifestations of HLH.

NK cell activity is a measure of the degree of target cell destruction by culturing NK cells isolated from the patient's blood and target cells (K562 cell line) together, based on flow cytometry. It is a test that requires blood from a non-affected person for use as the control. The normal value has been reported as $11.8-31.9 \%$ in Korea [36]. This is a very specific test for the diagnosis of HLH, but it is limited in that it can be performed only in some institutions in Korea. Soluble interleukin-2 receptor (sIL-2R) levels have been included in the diagnostic criteria and reflect the prognosis [37]. Even though it is a useful test, it is not conducted in Korea.

Serum ferritin is also included in the HLH-2004 diagnostic criteria because this test has the advantages of having a rapid turnaround time and being easy to perform, unlike the aforementioned special tests. A study of children [38] reported that the sensitivity/specificity of HLH diagnosis was $90 \% / 96 \%$, respectively, when the serum ferritin level exceeded 10,000 $\mu \mathrm{g} / \mathrm{L}$. However, in adults, unlike children, serum ferritin is often elevated in conditions unrelated to HLH. If the serum ferritin level is high, HLH may be suspected, but the diagnosis is not confirmed. According to a recent report [39], of 113 adults with a serum ferritin level of exceeding 50,000 $\mu \mathrm{g} / \mathrm{L}$, only 19 were actually diagnosed with HLH, and their median serum ferritin level was 99,000 $\mu \mathrm{g} / \mathrm{L}$. In cases of hepatocyte damage, infection, hematologic cancer, rheumatic disease, and hemolytic anemia, serum ferritin levels were similar to or rather lower than the median value of the measured values.

As such, the test results included in the diagnostic criteria for HLH in themselves are not specific for HLH. In addition, depending on how these findings are interpreted, patients with severe infections and other diseases are often suspected of having $\mathrm{HLH}$, although they do not match the typical clinical manifestations of HLH. Therefore, when diagnosing $\mathrm{HLH}$, it is important that an experienced hematologist judges the clinical aspects, rather than basing it on the diagnostic criteria alone, and a treatment decision should be made by considering the benefits and drawbacks of performing HLH-related treatment.

\section{DIFFERENTIAL DIAGNOSIS}

HLH is often mistaken for infection with severe sepsis, and its diagnosis is often delayed. In contrast, when a patient with a serious infection of uncertain cause is suspected of having HLH and this is confirmed based on the diagnostic criteria, a rapid diagnosis can be made within 3-5 days. Thus, diagnosis is based on a combination of clinical features and several test results; thus, its application is likely to be ambiguous. As a result, it is very difficult to diagnose HLH if it is not suspected; however, there are contradicting aspects that may cause an error of misdiagnosing another disease as HLH. To compensate for this, NK cell activity and gene mutation tests can be performed complementarily, but in reality, accurate differential diagnosis may be very difficult because the number of institutions that can be tested is limited and it takes considerable time to report the results [40]. Macrophage activation syndrome (MAS) may occur in patients with rheumatic disease and has clinical features very similar to those of HLH; thus, it is currently considered to be HLH caused by rheumatic disease [41].

As a factor that can explain the difference between the various clinical manifestations, including the differences in the clinical manifestations of HLH in adults and children, as mentioned above, evidence suggests that the patterns of genetic variation are different. Pediatric HLH, adult HLH, MAS, and systemic inflammatory response syndrome (SIRS) have different thresholds for activating the immune system, depending on the type and degree of polymorphism or mutation of various genes that are ultimately associated with the activation/deactivation of the immune system. One model explains that clinical aspects differ according to the problem (Fig. 2).

Hemophagocytosis is one of the diagnostic criteria for $\mathrm{HLH}$, and because of its name, it is often misunderstood as being the same as that of HLH. However, hemophagocytosis is a non-specific phenomenon that can also appear in other diseases such as infection, tumor, and rheumatism, whereas HLH can be diagnosed in the absence of hemophagocytosis [42]. Therefore, in the diagnosis of HLH, it is more important for an experienced clinician to identify the disease by synthesizing clinical manifestations and test results rather than basing it on the presence of hemophagocytosis.

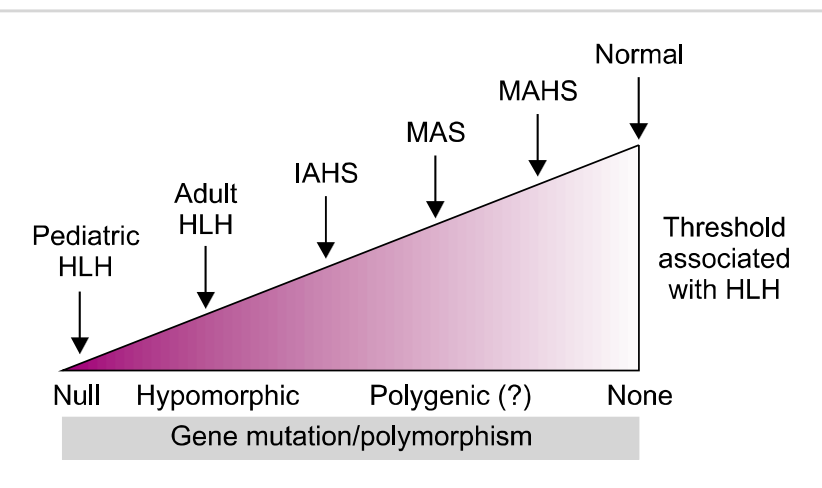

Fig. 2. The clinical manifestations of severe inflammatory diseases vary according to the genetic polymorphisms and mutations.

Abbreviations: HLH, hemophagocytic lymphohistiocytosis; IAHS, infectionassociated hemophagocytic syndrome; MAHS, malignancy-associated hemophagocytic syndrome; MAS, macrophage activation syndrome. 


\section{TREATMENT}

First, immunosuppressants are administered to suppress the overactivation of the immune system, which is the main pathogenesis of HLH, to prevent various side effects caused by cytokines secreted from immune cells. However, in this process, the frequency of various opportunistic infections increases, which increases treatment-related mortality. Thus, the administration of prophylactic antibiotic, antifungal, and antiviral agents is also important. If control is not achieved with such immunosuppressive treatment alone, administration of a cytotoxic anticancer drug capable of removing excessively proliferated T cells and NK cells should be attempted [43].

Immunosuppressant effects are usually achieved by administering cyclosporine and dexamethasone. In addition to the general role of corticosteroids in improving inflammation, suppressing the secretion of cytokines, and killing lymphocytes, dexamethasone is preferred because of its ability to penetrate the central nervous system better than other steroids. As a cytotoxic anticancer agent, etoposide-based therapy or CHOP (cyclophosphamide, vincristine, doxorubicin, prednisolone) therapy, which is applied for lympho$\mathrm{ma}$, is sometimes used. In the case of central nervous system involvement, intrathecal methotrexate injection is used.

The most widely used therapy based on etoposide is the HLH-2004 therapy, which was used in a multicenter clinical study in children; it is a modified/complementary therapy built on the results of the HLH-94 therapy [34, 44]. The prospective clinical study HLH-2004 was performed in children by applying this standard, and although this treatment is widely used to date, efforts have been made to revise it due to some uncertainties [45]. Of the 249 pediatric patients treated with the HLH-94 therapy, 124 (50\%) received allogeneic hematopoietic stem cell transplantation (HSCT), and a 3 -year survival rate of $55 \%$ was reported.

Etoposide is a key drug in the treatment of HLH, and in a retrospective study of pediatric patients with HLH associated with EBV infection, the administration of etoposide within 4 weeks had a significantly higher 4 -year survival rate than the administration without etoposide $(90.4 \%$ vs. $56.5 \%, P<0.01)$. By combining the above results, a prospective study was conducted to evaluate the effectiveness of HLH-2004, an immuno-cancer chemotherapy based on the administration of etoposide and early administration of immunosuppressants, by modifying HLH-94 [34].

In addition to such immuno-chemotherapy, it is essential to perform allogeneic hematopoietic stem cell treatment (HSCT) when the disease is refractory to the initial treatment or is reactivated, or when primary HLH is diagnosed. After allogeneic HSCT, the long-term survival rate is approximately 22-59\% [22, 46-48]. Factors influencing transplant-related prognosis are the inducing factors for HLH, involvement of the central nervous system, disease status at the time of transplantation [49], and donor type. The type of pre-transplantation treatment [50] and whether pre-dose treatment was performed $[51,52]$ are factors influencing transplant-related prognosis.

In case of disease that is refractory to treatment or reactivates, there is still no effective salvage therapy that can be performed before proceeding to allogeneic HSCT, even though the combination of antithymocyte globulin and steroids has been suggested [53]. Additionally, the results of trials of rituximab [54] and infliximab [55] have been reported in case studies. Recent studies have reported that ruxolitinib could be an effective and safe therapeutic option in refractory/relapsed HLH [56, 57].

Table 3. Results of studies on the treatment of hemophagocytic lymphohistiocytosis in adult patients.

\begin{tabular}{|c|c|c|c|c|c|c|}
\hline Authors & Characteristics & $N$ & Cause & Treatment & Outcome & Etc \\
\hline $\begin{array}{l}\text { Imashuku } \\
\text { et al. [60] } \\
\text { (Japan) }\end{array}$ & $\begin{array}{l}\text { Early vs. delayed } \\
\text { etoposide }\end{array}$ & 20 & EBV-HLH & $\begin{array}{l}\text { Etoposide } \\
\quad \text { (within } 4 \text { weeks) }\end{array}$ & Survivor: $5 / 7$ vs. $1 / 13$ & $\begin{array}{l}2.5-y r \text { OS: } \\
85 \text { vs. } 10 \%\end{array}$ \\
\hline $\begin{array}{l}\text { Tseng et al. } \\
\text { [63] (Taiwan) }\end{array}$ & $\begin{array}{l}\text { Non-infectious vs. } \\
\text { Infectious }\end{array}$ & 96 & $\begin{array}{l}\text { Non-infection: } 66 \\
\text { Infectious: } 30\end{array}$ & Observational study & Mortality: $70 \%$ vs. $47 \%$ & \\
\hline $\begin{array}{l}\text { Buyse et al. } \\
\text { [59] (France) }\end{array}$ & $\mathrm{HLH}$ at ICU & 56 & $\begin{array}{l}\text { Tumor: } 43 \\
\text { Non-viral: } 13 \\
\text { Viral: } 10\end{array}$ & $\begin{array}{l}\text { Etoposide: } 45 \\
\text { Corticosteroid: } 31 \\
\text { IVIG: } 3\end{array}$ & Mortality: 29/56 & $\begin{array}{l}\text { MAHS } \\
\text { Aggressive supportive } \\
\text { care }\end{array}$ \\
\hline $\begin{array}{l}\text { Park et al. } \\
\text { [61] (Korea) }\end{array}$ & $\begin{array}{l}\text { HLH with } \\
\text { hemophagocytosis }\end{array}$ & 23 & $\begin{array}{l}\text { EBV: } 16 \\
\text { Idiopathic: } 6 \\
\text { Hepatitis A: } 1\end{array}$ & $\begin{array}{l}\mathrm{HLH}-94 \text { or } 2004: 13 \\
\text { Immunosuppressive } \\
\text { therapy: } 9\end{array}$ & $\begin{array}{l}\text { Long-term } \\
\text { survivor: } 6 / 23(26 \%)\end{array}$ & $\begin{array}{l}4 \text { survivors received } \\
\text { alloHCT }\end{array}$ \\
\hline $\begin{array}{l}\text { Yoon et al. } \\
\text { [64] (Korea) }\end{array}$ & $\begin{array}{l}\text { Non malignancy } \\
\text { associated HLH }\end{array}$ & 126 & $\begin{array}{l}\text { EEBV, infection, } \\
\text { autoimmune }\end{array}$ & HLH-94 81 (64.3\%) & CR: $64.3 \%$ & $\begin{array}{l}\text { 8-week treatment } \\
\text { response is a predictor } \\
\text { for survival }\end{array}$ \\
\hline $\begin{array}{l}\text { Shin et al. } \\
\text { [62] (Korea) }\end{array}$ & CHOP-based Tx & 17 & & $\mathrm{CHOP}$ & $\begin{array}{l}\text { CR: } 41.2 \% \\
\text { PR: } 17.6 \%\end{array}$ & 2-year OS rate: $43.9 \%$ \\
\hline
\end{tabular}

Abbreviations: CHOP, cyclophosphamide/doxorubicin/vincristine/prednisolone; CR, complete remission; EBV, EpsteinBarr virus; HLH, hemophagocytic lymphohistiocytosis; ICU, intensive care unit; IVIG, intravenous immunoglobulin; MAHS, malignancy-associated hemophagocytic syndrome; OS, overall survival; PR, partial remission. 


\section{CONSIDERATIONS IN THE TREATMENT OF ADULT PATIENTS}

As mentioned above, adult HLH in the pattern of triggering factors, and acquired HLH, such as by tumor, infection, and rheumatism, is more frequent than primary $\mathrm{HLH}$, and tumors account for a significant number of these cases [3, 58]. There is no established therapy for adult HLH, and most treatments are shared with that for children, or complex chemotherapy used for lymphoma is applied. Reported treatment outcomes in adult HLH are shown in Table 3 [59-64]. Most of these are retrospective studies, and there have been no large-scale prospective studies to date.

It has not been evaluated whether it is appropriate to administer the same dose in elderly adults with low tolerance of the drug as that administered in children. As reported in small studies conducted in Korea, poor treatment outcomes in adult HLH are mainly due to the progression of multiple organ failure related to delayed diagnosis, leading to an irreversible state and frequent complications such as infection during treatment. To improve treatment outcomes in adults, rapid treatment initiation following early diagnosis [61, 65], modification of drug types and doses in consideration of disease severity and tolerability [37, 66-68], and biotechnology for predicting prognosis are required.

According to a report by Park et al. [61], patients with high serum fibrin source at the time of diagnosis showed a better prognosis, and all patients who received allogeneic HSCT survived, regardless of whether they received treatment with a regimen containing etoposide. This study suggested that long-term survival can be obtained by HSCT as early as possible while remission is maintained.

Treatment for HLH caused by infections, such as EBV, and triggers other than idiopathic HLH remains unclear. In HLH-2004, a multicenter prospective study conducted in children, the inclusion criteria were limited to EBV/congenital/idiopathic HLH, while the exclusion criterion was HLH related to rheumatism/tumor. For rheumatism-related $\mathrm{HLH}$, according to some experts' opinions, chemotherapy including etoposide will not be helpful, and thus, a careful approach is required [69]. Patients with lymphoma who have tumor-related HLH can be expected to respond, but the duration of response is short and the recurrence rate is high, according to a study from Korea [70].

Prospective studies are needed for the development of markers [61, 71, 72] and the development of treatments focusing on intensive infection prevention. In particular, rheumatism- or tumor-related HLH is regarded as a separate disease group, and individualized prospective studies according to the characteristics of the disease are required.

\section{REAL-WORLD HLH TREATMENT}

As mentioned above, it may be very difficult to distinguish between SIRS, MAS, etc., and HLH, and it may be time-con- suming to obtain an accurate differential diagnosis. To improve the prognosis of HLH, clinical suspicion and early diagnosis using HLH-2004 criteria is essential. If the diagnostic criteria are met, rapid administration of immuno-chemotherapy is important. However, if a severe infection is mistaken for HLH, then the administration of such a treatment can lead to serious consequences. Care should be taken against prematurely administering immune-chemotherapy without sufficiently excluding the possibility of other diseases. It is necessary to discriminate these diseases sufficiently by means of the tests presented in Table 4 . When the patient's condition deteriorates rapidly, there is not enough time to exclude the possibility of other diseases, and when administration of immune-chemotherapy is considered, the risk-benefit should be considered cautiously and the administration should be initiated by carefully judging whether it will be helpful to the patient.

\section{PROGNOSIS}

The factors that can predict the prognosis of HLH have not been clearly established. However, if the disease underlying HLH is a tumor, it is worse than when HLH is related to infection, rheumatism, or is congenital [73, 74]. Although the diagnostic value of serum ferritin for HLH is low, the degree of decrease in ferritin at the beginning of treatment has been reported to be associated with treatment-dependent prognosis [71]. Additionally, it has been reported that the higher the sIL-2R levels are, the worse is the prognosis [37]. In Korea, it has been reported that serum fibrinogen, along with serum ferritin, is related to prognosis [61]. Moreover, a previous study reported that the period from diagnosis to the administration of etoposide is associated with prognosis [75].

To improve the prognosis of HLH, it is important to suspect

Table 4. Diagnostic workup to differentiate hemophagocytic lymphohistiocytosis from other diseases.

\begin{tabular}{|c|c|}
\hline $\begin{array}{c}\text { Differential } \\
\text { diagnosis }\end{array}$ & Tests \\
\hline Malignancy & $\begin{array}{l}\text { Bone marrow aspiration/biopsy } \\
\text { Neck/chest/abdominopelvic computed } \\
\text { tomography } \\
\text { Tumor markers }\end{array}$ \\
\hline Infection & $\begin{array}{l}\text { Cytomegalovirus, Epstein-Barr virus, } \\
\text { parvovirus } \\
\text { Hepatitis A, B, C virus } \\
\text { Human immunodeficiency virus } \\
\text { Immunoglobulin E } \\
\text { Parasite-specific antibody }\end{array}$ \\
\hline Rheumatic disorder & $\begin{array}{l}\text { Fluorescence anti-nuclear } \\
\text { antibodyanti-double-strand DNA } \\
\text { C3/C4 } \\
\text { Erythrocyte sediment rate } \\
\text { Lupus anticoagulant }\end{array}$ \\
\hline
\end{tabular}


HLH at an early stage, diagnose it, and promptly administer immunotherapy. If there are symptoms such as fever/cytopenia/hepatic or splenic enlargement, HLH should be suspected. Serum triglycerides, fibrinogen, ferritin, etc. can be evaluated to confirm whether the diagnostic criteria are satisfied and that at least three or four of the eight criteria are satisfied. It is necessary to conduct a bone marrow examination and a biopsy of the involved organs promptly to assess the presence of hemophagocytosis and to exclude lymphomas. Moreover, it is necessary to evaluate NK cell activity and sIL-2R early, until the results are confirmed. In addition, tests to rule out infection and rheumatic diseases need to be conducted promptly. The association with Epstein-Barr virus needs to be established. If HLH is strongly suspected clinically, then it is very important to administer immuno-chemotherapy that includes etoposide before the disease progresses to serious organ failure.

\section{CONCLUSION}

It is believed that many of the diseases manifesting as pancytopenia and organ failure with high fever of unknown cause may be HLH. HLH is a phenomenon in which the process of inactivation of the immune system that has been activated by stimulation is impaired; overactive immune cells invade organs, and hypersecretion of cytokines result in organ failure. In adults, it has secondary causes such as infection, tumor, and rheumatism. Genetic alterations causing HLH, such as abnormalities of genes related to the inactivation of immune cells, have been discovered in adults. For the diagnosis and treatment of adult HLH, the HLH-2004 diagnostic criteria are used and treatment includes immuno-oncology chemotherapy, such as etoposide, and allogeneic HSCT. Appropriate diagnostic criteria and treatments for adult patients should be identified in the future.

Compared to children, the prognosis of adult HLH is poor. This is because HLH is often not initially suspected, and treatment is frequently initiated after irreversible organ damage has occurred. Moreover, reactivation occurs in many patients in the absence of effective rescue therapy. To improve the prognosis of adult HLH, it is necessary to develop a treatment model that can predict the treatment response and prognosis, facilitating customized treatment according to the disease severity. Moreover, it is necessary to minimize the time to diagnosis and treatment. Lastly, effective salvage therapy should be ascertained. It would be important to identify the high-risk patients and, if possible, to perform allogeneic HSCT early while maintaining remission.

\section{Authors' Disclosures of Potential Conflicts of Interest}

No potential conflicts of interest relevant to this article were reported.

\section{REFERENCES}

1. Filipovich AH. Hemophagocytic lymphohistiocytosis and other hemophagocytic disorders. Immunol Allergy Clin North Am 2008;28:293-313, viii.

2. Janka GE, Lehmberg K. Hemophagocytic syndromes--an update. Blood Rev 2014;28:135-42.

3. Ramos Casals M, Brito Zerón P, López Guillermo A, Khamashta MA, Bosch X. Adult haemophagocytic syndrome. Lancet 2014; 383:1503-16.

4. Ishii E, Ohga S, Imashuku S, et al. Nationwide survey of hemophagocytic lymphohistiocytosis in Japan. Int J Hematol 2007;86:58-65.

5. de Kerguenec C, Hillaire S, Molinié V, et al. Hepatic manifestations of hemophagocytic syndrome: a study of 30 cases. Am J Gastroenterol 2001;96:852-7.

6. Karras A, Thervet E, Legendre C; Groupe Coopératif de transplantation d'Ile de France. Hemophagocytic syndrome in renal transplant recipients: report of 17 cases and review of literature. Transplantation 2004;77:238-43.

7. Thaunat O, Delahousse M, Fakhouri F, et al. Nephrotic syndrome associated with hemophagocytic syndrome. Kidney Int 2006;69: 1892-8.

8. Henter JI, Nennesmo I. Neuropathologic findings and neurologic symptoms in twenty-three children with hemophagocytic lymphohistiocytosis. J Pediatr 1997;130:358-65.

9. Fukaya S, Yasuda S, Hashimoto T, et al. Clinical features of haemophagocytic syndrome in patients with systemic autoimmune diseases: analysis of 30 cases. Rheumatology (Oxford) 2008;47: 1686-91.

10. Jordan MB, Allen CE, Weitzman S, Filipovich AH, McClain KL. How I treat hemophagocytic lymphohistiocytosis. Blood 2011; 118:4041-52.

11. Griffin G, Shenoi S, Hughes GC. Hemophagocytic lymphohistiocytosis: an update on pathogenesis, diagnosis, and therapy. Best Pract Res Clin Rheumatol 2020;34:101515.

12. Egeler RM, Shapiro R, Loechelt B, Filipovich A. Characteristic immune abnormalities in hemophagocytic lymphohistiocytosis. J Pediatr Hematol Oncol 1996;18:340-5.

13. McCall CM, Mudali S, Arceci RJ, et al. Flow cytometric findings in hemophagocytic lymphohistiocytosis. Am J Clin Pathol 2012; 137:786-94.

14. Jordan MB, Hildeman D, Kappler J, Marrack P. An animal model of hemophagocytic lymphohistiocytosis (HLH): CD8+ T cells and interferon gamma are essential for the disorder. Blood 2004; 104:735-43.

15. Kögl T, Müller J, Jessen B, et al. Hemophagocytic lymphohistiocytosis in syntaxin-11-deficient mice: T-cell exhaustion limits fatal disease. Blood 2013;121:604-13.

16. Gholam C, Grigoriadou S, Gilmour KC, Gaspar HB. Familial haemophagocytic lymphohistiocytosis: advances in the genetic basis, diagnosis and management. Clin Exp Immunol 2011;163: 271-83.

17. Horne A, Ramme KG, Rudd E, et al. Characterization of PRF1, STX11 and UNC13D genotype-phenotype correlations in familial hemophagocytic lymphohistiocytosis. Br J Haematol 2008;143: 
75-83.

18. Marsh RA, Satake N, Biroschak J, et al. STX11 mutations and clinical phenotypes of familial hemophagocytic lymphohistiocytosis in North America. Pediatr Blood Cancer 2010;55:134-40.

19. Meeths M, Chiang SC, Wood SM, et al. Familial hemophagocytic lymphohistiocytosis type 3 (FHL3) caused by deep intronic mutation and inversion in UNC13D. Blood 2011;118:5783-93.

20. Yoon HS, Kim HJ, Yoo KH, et al. UNC13D is the predominant causative gene with recurrent splicing mutations in Korean patients with familial hemophagocytic lymphohistiocytosis. Haematologica 2010;95:622-6.

21. Arico M, Imashuku S, Clementi R, et al. Hemophagocytic lymphohistiocytosis due to germline mutations in SH2D1A, the X-linked lymphoproliferative disease gene. Blood 2001;97: 1131-3.

22. Henter JI. Biology and treatment of familial hemophagocytic lymphohistiocytosis: importance of perforin in lymphocytemediated cytotoxicity and triggering of apoptosis. Med Pediatr Oncol 2002;38:305-9.

23. Feldmann J, Callebaut I, Raposo G, et al. Munc13-4 is essential for cytolytic granules fusion and is mutated in a form of familial hemophagocytic lymphohistiocytosis (FHL3). Cell 2003;115: 461-73.

24. Janka G, Imashuku S, Elinder G, Schneider M, Henter JI. Infectionand malignancy-associated hemophagocytic syndromes. Secondary hemophagocytic lymphohistiocytosis. Hematol Oncol Clin North Am 1998;12:435-44.

25. Machaczka $M$, Vaktnäs J, Klimkowska $M$, Hägglund $H$. Malignancy-associated hemophagocytic lymphohistiocytosis in adults: a retrospective population-based analysis from a single center. Leuk Lymphoma 2011;52:613-9.

26. Machaczka M, Vaktnäs J, Klimkowska M, Nahi H, Hägglund H. Acquired hemophagocytic lymphohistiocytosis associated with multiple myeloma. Med Oncol 2011;28:539-43.

27. Meki A, O'Connor D, Roberts C, Murray J. Hemophagocytic lymphohistiocytosis in chronic lymphocytic leukemia. J Clin Oncol 2011;29:e685-7.

28. Mulay S, Bauer F, Boruchov A, Bilgrami S. Successful resolution of acute myelogenous leukemia-associated hemophagocytic lymphohistiocytosis with decitabine. Leuk Lymphoma 2011;52: 341-3.

29. Nagafuji K, Nonami A, Kumano T, et al. Perforin gene mutations in adult-onset hemophagocytic lymphohistiocytosis. Haematologica 2007;92:978-81.

30. Zhang K, Jordan MB, Marsh RA, et al. Hypomorphic mutations in PRF1, MUNC13-4, and STXBP2 are associated with adult-onset familial HLH. Blood 2011;118:5794-8.

31. Koh KN, Im HJ, Chung NG, et al. Clinical features, genetics, and outcome of pediatric patients with hemophagocytic lymphohistiocytosis in Korea: report of a nationwide survey from Korea Histiocytosis Working Party. Eur J Haematol 2015;94:51-9.

32. Sumegi J, Barnes MG, Nestheide SV, et al. Gene expression profiling of peripheral blood mononuclear cells from children with active hemophagocytic lymphohistiocytosis. Blood 2011;117: e151-60.

33. Sumegi J, Nestheide SV, Barnes MG, et al. Gene-expression signatures differ between different clinical forms of familial hemophagocytic lymphohistiocytosis. Blood 2013;121:e14-24.

34. Henter J, Horne A, Aricó M, et al. HLH-2004: diagnostic and therapeutic guidelines for hemophagocytic lymphohistiocytosis. Pediatr Blood Cancer 2007;48:124-31.

35. Chen JH, Fleming MD, Pinkus GS, et al. Pathology of the liver in familial hemophagocytic lymphohistiocytosis. Am J Surg Pathol 2010;34:852-67.

36. Chung HJ, Park CJ, Lim JH, et al. Establishment of a reference interval for natural killer cell activity through flow cytometry and its clinical application in the diagnosis of hemophagocytic lymphohistiocytosis. Int J Lab Hematol 2010;32:239-47.

37. Imashuku S, Hibi S, Sako M, et al. Soluble interleukin-2 receptor: a useful prognostic factor for patients with hemophagocytic lymphohistiocytosis. Blood 1995;86:4706-7.

38. Allen CE, Yu X, Kozinetz CA, McClain KL. Highly elevated ferritin levels and the diagnosis of hemophagocytic lymphohistiocytosis. Pediatr Blood Cancer 2008;50:1227-35.

39. Schram AM, Campigotto F, Mullally A, et al. Marked hyperferritinemia does not predict for HLH in the adult population. Blood 2015;125:1548-52.

40. Raschke RA, Garcia-Orr R. Hemophagocytic lymphohistiocytosis: a potentially underrecognized association with systemic inflammatory response syndrome, severe sepsis, and septic shock in adults. Chest 2011;140:933-8.

41. Félix FH, Leal LK, Fontenele JB. Cloak and dagger: the case for adult onset still disease and hemophagocytic lymphohistiocytosis. Rheumatol Int 2009;29:973-4.

42. Gupta A, Weitzman S, Abdelhaleem M. The role of hemophagocytosis in bone marrow aspirates in the diagnosis of hemophagocytic lymphohistiocytosis. Pediatr Blood Cancer 2008;50:192-4.

43. Imashuku S. Advances in the management of hemophagocytic lymphohistiocytosis. Int J Hematol 2000;72:1-11.

44. Henter JI, Samuelsson-Horne A, Aricò M, et al. Treatment of hemophagocytic lymphohistiocytosis with HLH-94 immunochemotherapy and bone marrow transplantation. Blood 2002; 100:2367-73.

45. Filipovich AH. Hemophagocytic lymphohistiocytosis (HLH) and related disorders. Hematology Am Soc Hematol Educ Program 2009:127-31.

46. Aricò M, Janka G, Fischer A, et al. Hemophagocytic lymphohistiocytosis. Report of 122 children from the International Registry. FHL Study Group of the Histiocyte Society. Leukemia 1996;10:197-203.

47. Baker KS, DeLaat CA, Steinbuch M, et al. Successful correction of hemophagocytic lymphohistiocytosis with related or unrelated bone marrow transplantation. Blood 1997;89:3857-63.

48. Cesaro S, Locatelli F, Lanino E, et al. Hematopoietic stem cell transplantation for hemophagocytic lymphohistiocytosis: a retrospective analysis of data from the Italian Association of Pediatric Hematology Oncology (AIEOP). Haematologica 2008; 93:1694-701.

49. Horne A, Janka G, Maarten Egeler R, et al. Haematopoietic stem cell transplantation in haemophagocytic lymphohistiocytosis. $\mathrm{Br}$ J Haematol 2005;129:622-30.

50. Jabado N, de Graeff-Meeder ER, Cavazzana-Calvo M, et al. Treatment of familial hemophagocytic lymphohistiocytosis with bone marrow transplantation from HLA genetically nonidentical 
donors. Blood 1997;90:4743-8.

51. Cooper N, Rao K, Gilmour K, et al. Stem cell transplantation with reduced-intensity conditioning for hemophagocytic lymphohistiocytosis. Blood 2006;107:1233-6.

52. Marsh RA, Vaughn G, Kim MO, et al. Reduced-intensity conditioning significantly improves survival of patients with hemophagocytic lymphohistiocytosis undergoing allogeneic hematopoietic cell transplantation. Blood 2010;116:5824-31.

53. Mahlaoui N, Ouachée-Chardin M, de Saint Basile G, et al. Immunotherapy of familial hemophagocytic lymphohistiocytosis with antithymocyte globulins: a single-center retrospective report of 38 patients. Pediatrics 2007;120:e622-8.

54. Balamuth NJ, Nichols KE, Paessler M, Teachey DT. Use of rituximab in conjunction with immunosuppressive chemotherapy as a novel therapy for Epstein Barr virus-associated hemophagocytic lymphohistiocytosis. J Pediatr Hematol Oncol 2007;29:569-73.

55. Ideguchi H, Ohno S, Takase K, et al. Successful treatment of refractory lupus-associated haemophagocytic lymphohistiocytosis with infliximab. Rheumatology (Oxford) 2007;46:1621-2.

56. Wang J, Wang Y, Wu L, et al. Ruxolitinib for refractory/relapsed hemophagocytic lymphohistiocytosis. Haematologica 2020;105: e210-2.

57. Ahmed A, Merrill SA, Alsawah F, et al. Ruxolitinib in adult patients with secondary haemophagocytic lymphohistiocytosis: an open-label, single-centre, pilot trial. Lancet Haematol 2019; 6:e630-7.

58. Lehmberg K, Nichols KE, Henter JI, et al. Consensus recommendations for the diagnosis and management of hemophagocytic lymphohistiocytosis associated with malignancies. Haematologica 2015;100:997-1004.

59. Buyse S, Teixeira L, Galicier L, et al. Critical care management of patients with hemophagocytic lymphohistiocytosis. Intensive Care Med 2010;36:1695-702.

60. Imashuku S, Kuriyama K, Sakai R, et al. Treatment of Epstein-Barr virus-associated hemophagocytic lymphohistiocytosis (EBV-HLH) in young adults: a report from the HLH study center. Med Pediatr Oncol 2003;41:103-9.

61. Park HS, Kim DY, Lee JH, et al. Clinical features of adult patients with secondary hemophagocytic lymphohistiocytosis from causes other than lymphoma: an analysis of treatment outcome and prognostic factors. Ann Hematol 2012;91:897-904.

62. Shin HJ, Chung JS, Lee JJ, et al. Treatment outcomes with CHOP chemotherapy in adult patients with hemophagocytic lymphohistiocytosis. J Korean Med Sci 2008;23:439-44.

63. Tseng YT, Sheng WH, Lin BH, et al. Causes, clinical symptoms, and outcomes of infectious diseases associated with hemophagocytic lymphohistiocytosis in Taiwanese adults. J Microbiol Immunol Infect 2011;44:191-7.

64. Yoon JH, Park SS, Jeon YW, et al. Treatment outcomes and prognostic factors in adult patients with secondary hemophagocytic lymphohistiocytosis not associated with malignancy. Haematologica 2019;104:269-76.

65. Jin YK, Xie ZD, Yang S, Lu G, Shen KL. Epstein-Barr virusassociated hemophagocytic lymphohistiocytosis: a retrospective study of 78 pediatric cases in mainland of China. Chin Med J (Engl) 2010;123:1426-30.

66. Belyea B, Hinson A, Moran C, Hwang E, Heath J, Barfield R. Spontaneous resolution of Epstein-Barr virus-associated hemophagocytic lymphohistiocytosis. Pediatr Blood Cancer 2010;55: 754-6.

67. Gupta AA, Tyrrell P, Valani R, Benseler S, Abdelhaleem M, Weitzman S. Experience with hemophagocytic lymphohistiocytosis/ macrophage activation syndrome at a single institution. J Pediatr Hematol Oncol 2009;31:81-4.

68. Imashuku S. Treatment of Epstein-Barr virus-related hemophagocytic lymphohistiocytosis (EBV-HLH); update 2010. J Pediatr Hematol Oncol 2011;33:35-9.

69. Gansner JM, Berliner N. The rheumatology/hematology interface: CAPS and MAS diagnosis and management. Hematology Am Soc Hematol Educ Program 2018;2018:313-7.

70. Yoon SE, Eun Y, Huh K, et al. A comprehensive analysis of adult patients with secondary hemophagocytic lymphohistiocytosis: a prospective cohort study. Ann Hematol 2020;99:2095-104.

71. Lin TF, Ferlic-Stark LL, Allen CE, Kozinetz CA, McClain KL. Rate of decline of ferritin in patients with hemophagocytic lymphohistiocytosis as a prognostic variable for mortality. Pediatr Blood Cancer 2011;56:154-5.

72. Takada H, Nomura A, Ohga S, Hara T. Interleukin-18 in hemophagocytic lymphohistiocytosis. Leuk Lymphoma 2001; 42:21-8.

73. Otrock ZK, Eby CS. Clinical characteristics, prognostic factors, and outcomes of adult patients with hemophagocytic lymphohistiocytosis. Am J Hematol 2015;90:220-4.

74. Rivière $\mathrm{S}$, Galicier L, Coppo $\mathrm{P}$, et al. Reactive hemophagocytic syndrome in adults: a retrospective analysis of 162 patients. Am J Med 2014;127:1118-25.

75. Imashuku S, Kuriyama K, Teramura T, et al. Requirement for etoposide in the treatment of Epstein-Barr virus-associated hemophagocytic lymphohistiocytosis. J Clin Oncol 2001;19: 2665-73. 